\title{
VERSO Y PROSA EN LA ETAPA AMERICANA DE JUAN RAMÓN JIMÉNEZ
}

\author{
Miguel Ángel Márquez
}

\section{ESPACIO}

Tuan Ramón Jiménez, con 59 años de edad, en la Florida, tras otro internamiento hospitalario, y después de casi un lustro sin escribir poesía alguna, inició una nueva etapa de su “Obra”. Era enero de 1941, cuando comenzó a escribir Espacio; poco antes, una madrugada se encontró componiendo romances y canciones, como sabemos por una carta a Enrique Díez-Canedo (6 de agosto de 1943), muchas veces reproducida:

En la Florida empecé a escribir otra vez en verso. Antes, por Puerto Rico y Cuba, había escrito casi esclusivamente crítica y conferencias. Una madrugada me encontré escribiendo unos romances y unas canciones que eran un retorno a mi primera juventud, una inoncencia última, un final lójico de mi última escritura sucesiva en España. [...] Pues en 1941, saliendo yo, casi nuevo, resucitado casi, del hospital de la Universidad de Miami [...], una embriaguez rapsódica, una fuga incontenible empezó a dictarme un poema de espacio, en una sola interminable estrofa de verso libre mayor. Y al lado de este poema y paralelo a él, como me ocurre siempre, vino a mi lápiz un interminable párrafo en prosa, dictado por la estensión lisa de la Florida, y que es una escritura de tiempo, fusión memorial de ideolojía y anécdota, sin orden cronolójico; como una tira sin fin desliada hacia atrás en mi vida. Estos libros se titulan, el primero, Espacio; el segundo, Tiempo, y se subtitulan Estrofa y Párrafo (Garfias, 1992: 243). 
La crítica parece estar de acuerdo en que Espacio es una poesía muy innovadora ${ }^{1}$ y su valor literario, sorprendente y excepcional. ${ }^{2}$ También Juan Ramón Jiménez expresó un juicio crítico positivo sobre Espacio, como se ve en la carta a Juan Larrea de 24 de julio de 1943 que acompaña el envío del primer fragmento para su publicación en Cuadernos Americanos: «Creo que es lo mejor que tengo ahora, y por eso va a esos Cuadernos» (Garfias, 1992: 237).

La historia textual de Espacio parece estar muy clara para la crítica (Albornoz, 1982: 66; Villar, 1986: 49; Alegre, 1999: 433436) y puede resumirse así: el libro se inició en enero de 1941 como poema en verso libre (denominación que le da Juan Ramón Jiménez y que la crítica ha aceptado); durante ese año y el siguiente, Juan Ramón Jiménez compuso los dos primeros fragmentos en verso. La revista Cuadernos Americanos (vol. XI, $\mathrm{n}^{\circ}$ 5, septiembre-octubre, 1943) publicó el primero de ellos como “Espacio (una estrofa)” y, al año siguiente (Cuadernos Americanos vol. XVII, $\mathrm{n}^{\circ}$ 5, septiembre-octubre, 1944), el segundo como “Espacio (Fragmento primero de la segunda estrofa). Cantada”. Por otra parte, diferentes segmentos de Espacio se publicaron en los años sucesivos como poemas independientes en verso libre. El 11 de enero de 1953, La Nación de Buenos Aires publicó una parte del fragmento tercero, en prosa. La versión definitiva de Espacio, tres fragmentos en prosa, vio la luz en la revista Poesía Española (abril de 1954). Esta versión se incluyó en la Tercera antolojía poética (1957). ${ }^{3}$

1 “Espacio, sencillamente, no era poesía como la que había urdido Juan Ramón hasta entonces” (Young, 1981: 190); Aurora de Albornoz (1982: 63) señala que Enrique Díez-Canedo creía que con Espacio se abría una nueva etapa en Juan Ramón Jiménez; para Villar (1986: 26) Espacio y Tiempo son excepciones en la obra de Juan Ramón; aunque quizá más que excepciones, sean los inicios de una nueva forma de escribrir poesía.

${ }^{2}$ Según Octavio Paz (1956: 94-95) “Espacio es uno de los monumentos de la conciencia poética moderna y con ese texto capital culmina la interrogación que el gran cisne hizo a Darío en su juventud”. Para Aurora de Albornoz "una de las máximas creaciones poéticas de este siglo, en cualquier lengua” (Albornoz, 1982: 63).

${ }^{3}$ Se conserva además un original mecanografiado con correcciones manuscritas de la versión en prosa, anterior a la publicación en Poesía Española; de este original existen ediciones facsímiles. 
Sin embargo, debemos tener en cuenta que conservamos una grabación de Juan Ramón Jiménez en la que recita varios poemas suyo y, entre ellos, el fragmento primero de Espacio. La versión que podemos oír de boca de Juan Ramón Jiménez difiere tanto de la primera versión (la publicada en verso por Cuadernos Americanos) como de la versión definitiva en prosa (publicada por Poesía Española). Podemos decir que es una versión intermedia, puesto que conserva versos de la primera versión que después fueron cambiados en la defintiva. ${ }^{4}$ Ahora bien, en otros casos la versión leída introduce cambios con respecto a la versión en verso libre que quedarán en la versión en prosa. ${ }^{5}$ Por otra parte, algún cambio introducido en la segunda versión es desechado en la definitiva que adopta la lectura de la primera. Por último, no faltan versos que muestran tres lecturas diferentes que corresponden a las tres versiones que conservamos. ${ }^{6}$

Mientras que la aceptación de la versión en verso libre de los dos primeros fragmentos nunca ha resultado problemática, ${ }^{7}$ la crítica no ha sabido comprender los motivos que indujeron a Juan Ramón Jiménez a publicar como prosa Espacio. Gerardo Diego, a pesar de que fue uno de los primeros críticos en señalar la importancia del poema cuando leyó su versión en verso libre (o quizá por eso mismo), personifica la incompresión extrema de este proceso:

[El poema Espacio] Presenta en la última disposición, la de Poesía Española, repetida en la Tercera Antolojía, un asustante aspecto de mazacote en prosa sin puntos y aparte. Capricho poco explicable

${ }^{4}$ Por ejemplo, Espacio 1.77: “delicado presente de oro ideal,” en la primera versión; "delicado presente de oro de ideal”, en la versión grabada; y "dedicado presente de oro de ideal”, en la versión definitiva.

${ }^{5}$ Por ejemplo, Espacio 1.410: “consuelo universal de hombre y mujer”, frente a la versión leída y a la definitiva: "consuelo universal de mujer y hombre”.

${ }^{6}$ Por ejempo, Espacio 1.276: “de la dulce obediente, plena gracia” (así en la primera y en la definitiva) frente a la lectura de la versión leída: "de la dulce obediente, gracia plena”.; o Espacio 1.451: “tú”; “y tú seas, seas”; “y tú seas” (véase igualmente el verso Espacio 1.453, que se comenta más abajo).

${ }^{7}$ Aunque no haya hasta ahora un análisis detallado del verso libre de Espacio. Para el verso libre juanramoniano en general, véase Paraíso (1985), dentro del tratamiento del verso libre hispánico. 
del poeta, como no sea por ahuyentar al filisteo y quedarse sólo con sus fieles (Gerardo Diego, 1984: 343). ${ }^{8}$

La explicación de Gerardo Diego como un «capricho de última hora» puede haber provocado la respuesta de Aurora de Albornoz, quien, a pesar de que contextualiza la "prosificación" de Espacio en un proceso más general, parece distinguirla de los otros casos:

en sus años últimos andaba poniendo en prosa lo antes escrito en verso libre. Sin embargo, en el caso de Espacio la alteración no obedece a capricho de última hora: se trata, a mi juicio, de una corrección necesaria (Albornoz, 1982: 69).

¿Quiere decir Aurora de Albornoz que en otros casos distintos de Espacio la prosificación era un capricho de Juan Ramón Jiménez, o que la prosificación de Espacio y de otros poemas pueden tener una razón y un objetivo distintos? Según Aurora de Albornoz el objetivo del poeta era lograr un "poema seguido" y para ello:

era necesario romper incluso con la tradicional distribución del texto en versos; era necesario el paso de líneas cortas y largas a esas líneas ininterrumpidas -que parecen prosa-que fluyen torrencialmente, desde el comienzo hasta el final, llenando de palabras las páginas; inundando de palabras el espacio de las páginas (Albornoz, 1982: 69).

Sin embargo, no se nos ofrece ninguna reflexión sobre la naturaleza de ese "poema seguido", que parece prosa pero que no es prosa. ¿Es, simplemente, poesía camuflada como prosa y Juan Ramón Jiménez se complace en utilizar un "engaño del

${ }^{8}$ Véase también: "Por un capricho de tantos como los que él abrazaba en un momento u otro de sus proyectos y de sus publicaciones terminó por publicar este poema como en prosa, en forma amazacotada, en apretados rectángulos de letra no grande, tal como apareció completo en la revista Poesía Española de Madrid” (Gerardo Diego, 1984: 344). 
ojo” plástico, casi pictórico, como sugiere la profesora Paraíso?9 Este tipo de explicación ofrece también H. Young:

el poeta quería libertarse de los recursos visuales tradicionalmente asociados con la poesía, la estrofa y la extensión del verso, los cuales, según él, no ayudaban al lector a entender mejor el verso libre (Young, 1981: 192).

Ahora bien, podemos preguntarnos si estas razones visuales, indiscutibles en la medida en que constatan la presentación del texto y nuestra visión del mismo explican todos los aspectos del fenómeno que tratamos.

En los dos últimos poemarios de Juan Ramón Jiménez (Dios deseado y deseante y De ríos que se van) hallamos el mismo fenómeno de "prosificación" que hemos visto respecto a Espacio. Por ejemplo, "El desnudo infinito" (Dios deseado y deseante) tuvo una primera versión en verso, titulada "No quiero exaltación de las eternidades” y que data del final del 1948, y otra definitiva en prosa, que Juan Ramón Jiménez fechó en 1950 (Alegre, 1999: 472) ${ }^{10}$ Otro ejemplo pertenece al poemario De ríos que se van: "Tú, animal hembra, mujer mía" se conserva en dos originales, el más antiguo sin título está escrito en verso y el más reciente, también en verso, lleva escrito de la mano de Juan Ramón Jiménez “En forma de prosa” (Alegre, 1999: 484).

Juan Ramón Jiménez pretendía publicar como prosa toda su poesía anterior escrita en verso libre. Es decir, pretendía extender retroactivamente su evolución personal en la concepción de las formas génericas de verso y prosa, a toda su obra y no sólo a la escrita en la etapa americana. Esta tendencia general de la última etapa de Juan Ramón Jiménez se cifran en la revisión total

\footnotetext{
9 “Y sólo la voluntad del poeta de verter sus poemas en la tipografía de la prosa, ese engaño de los ojos, [...]” (Paraíso, 1971: 264).

${ }^{10}$ Alegre (1999: 416-418) ofrece la versión en verso libre de "El desnudo infinito”, bajo el título "No quiero exaltación de las eternidades”, que puede verse en el Anexo correspondiente.
} 
de su poesía que dejó al morir (1958) y que ha sido editada con el título de Leyenda por A. Sánchez Romeralo (1978). ${ }^{11}$

\section{ANÁLISIS MÉTRICO DE LOS POEMAS ESCRITOS EN VERSO LIBRE}

Antes de abordar las relaciones de prosa y verso, parece conveniente describir el verso libre que utiliza Juan Ramón Jiménez en su etapa americana (Espacio, Dios deseado y deseante y De ríos que se van), porque sin duda puede ayudarnos a comprender mejor esas relaciones. Al margen del problema de cuándo entra el verso libre en su obra (Paraíso, 1985; Romero López de las Hazas, 1992) y de su origen en Unamuno, como apunta Juan Ramón Jiménez, debemos indagar en la clave el verso libre de nuestro poeta.

Para Juan Ramón Jiménez verso libre o “verso desnudo” es el verso sin rima, por eso dice de Espacio «una sola interminable estrofa de verso libre mayor». La profesora Paraíso acepta esta idea juanramoniana y añade que su verso libre es parecidísimo a la silva impar modernista:

La mayor diferencia entre el verso libre juanramoniano y su silva estriba en la carencia de rima (o uso de alguna asonancia dispersa y accidental); y, como diferencia menor, la posibilidad de que algún verso de otra medida (generalmente muy corta) pueda deslizarse (Paraíso, 1985: 203).

Creo que deberíamos partir de un análisis métrico exhaustivo de Espacio, para poder llegar a una nueva conclusión sobre la esencia de ese tipo de verso, se denomine como se denomine. Para ello he medido los 537 versos que lo componen. ¿Qué encontramos en Espacio?

${ }^{11}$ Según anota Urrutia, “en Leyenda, aparte de modificaciones y de reconstrucciones de los poemas, casi todos aquellos que fueron inicialmente escritos en verso libre adquieren forma de prosa” (Urrutia, 1981: 725). 


$\begin{array}{lrl}\text { Endecasílabos: } & 288 & (54 \%) \\ \text { Versos compuestos } & 129 & (24 \%) \\ \text { Eneasílabos: } & 67 & (12,5 \%) \\ \text { Heptasílabos: } & 39 & (7,3 \%) \\ \text { Resto } & 14 & (2,6 \%)\end{array}$

Más de la mitad de los versos son endecasílabos (54\%), que se combinan con heptasílabos, siguiendo la pauta de la silva clásica, pero mucho más con eneasílabos, desarrollando la innovación de la silva modernista. Los pentasílabos y otros versos cortos ocupan una posición marginal. Junto a estos versos simples, encontramos un grupo numerosísimo de versos compuestos $(24 \%) .{ }^{12}$

En un trabajo anterior (Márquez, 2000), he expuesto el modelo que propongo para explicar el verso libre de ritmo endecasilábico: la innovación fundamental del verso libre de ritmo endecasilábico (o como cada cual quiera llamarlo) frente a la silva modernista es la utilización de versos compuestos de dos o más hemistiquios distintos del alejandrino; esta innovación aparece en Unamuno pero con una frecuencia muy reducida; la desarrolla Juan Ramón Jiménez y llega a su culminación en algunos poetas del 27. Podemos denominar "versículo" a este verso compuesto. Sus componentes, sean dos o más, "hemistiquios" en un sentido lato permitido por el DRAE, presentan también el ritmo endecasilábico general, es decir, tienen número impar de sílabas (5, 7, 9 u 11 sílabas).

La clave del sistema es el versículo (En Espacio, nada menos que el 24\% del total de los versos), que cumple una doble función rítmica. Por una parte, innova la tradición porque no se parte de un metro fijo ni el receptor conoce el metro de antemano. Pero, por otra parte, su base rítmica es la tradicional de la poesía culta española y puede ser reconocida por el oído del receptor a pesar de la apariencia nueva y extraña. El versículo consigue renovar la métrica tradicional y permite, al mismo tiempo, que el

\footnotetext{
${ }^{12}$ No quiero entrar en un debate, pero me parece razonable aceptar como verso simple el que tiene once o menos sílabas, y verso compuesto el que tiene más de once sílabas.
} 
receptor se adapte al nuevo sistema inconscientemente. Además de esta función rítmica, el versículo ofrece variaciones estilísticas, pues enlentece el tiempo del poema con su tono más grave que el de los versos simples.

Como ejemplo de este tipo de análisis que propongo, veamos el comienzo de Espacio en su primera versión en verso libre (Espacio 1.1-9):

Los dioses no tuvieron más sustancia [11] que la que tengo yo. Yo tengo, como ellos, la sustancia de todo lo vivido

y de todo lo porvivir. No soy presente sólo, sino fuga raudal de cabo a fin. Y lo que veo a un lado y otro, en esta fuga, rosas, restos de alas, sombra y luz es sólo mío, $[9+7]$ $5[11+5,7+9]$

[9]

recuerdo y ansia míos, presentimiento, olvido. [ [7+7]

Este tipo de análisis, que sin duda tienes sus precedentes como señala Utrera (2001: 243), sólo será válido si se demuestra que el versículo es una realidad rítmica distinta a la serie de versos simples que resultaría de su descomposición. En el ejemplo anterior, no serían equivalentes los dos versículos de Espacio 1.4-5 y los cuatro versos que obtendríamos de su descomposición:

y de todo lo porvivir.

No soy presente sólo,

sino fuga raudal de cabo a fin.

Y lo que veo
9

7

11

Como es obvio, estamos cuestionando la existencia misma del versículo, la existencia métrica y rítmica del versículo, más allá del efecto visual que provocan las diferentes tipografías. La resolución del problema se basa en la distinción de la pausa de final de verso y la pausa de final de hemistiquio, distinción que no se ha hecho antes, según creo, y que no tiene precedentes. Resumo mi posición, expuesta en un trabajo anterior (Márquez, 2000). La teoría métrica no distingue ambas pausas por una serie 
de características comunes: 1) rechazan la sinalefa (salvo caso de sinafía); 2) igualan los finales agudos, llanos y esdrújulos; 3) delimitan verso y hemistiquio.

Pero propongo que distingamos ambas pausas basándonos en el concepto "tiempo del poema". El tiempo del poema (tempo) es la percepción emocional que se tiene del ritmo global de un poema y queda marcado por las pausas de final de verso, en las que se introduce un elemento rítmico esencial: el silencio, que rompe el desarrollo lineal y continuo del discurso. El verso es la unidad rítmica menor perteneciente a un plano no teórico: ${ }^{13}$ es el módulo más pequeño por el que se nos transmite el contenido poético. Si admitimos que el tiempo continuo de la realidad para transformarse en tiempo vivencial de la poesía (tiempo humanizado) debe hacerse discontinuo y ser capaz de soportar un ritmo, admitiremos igualmente que ese tiempo poético ya dividido debe coincidir con las unidades rítmicas menores, es decir, con los versos. El poeta nos envía la sustancia poética en "cuantos" sucesivos, de una manera rápida o lenta, constante o no, en lo que habitualmente se denomina segmentación del discurso poético.

La pausa de final de verso es una marca pertinente para el tiempo del poema. La pausa de final del hemistiquio, por el contrario, no lo es. Podemos partir de la intuición de que una serie de alejandrinos no equivale al conjunto de heptasílabos que resultaría de su descomposición. Pero incluso podemos percibir los distintos tiempos en el ejemplo anterior de Juan Ramón Jiménez. En resumen, si para el ritmo acentual el versículo es equivalente a la serie de versos simples que lo constituyen, para el tempo del poema de ninguna manera equivalen el versículo y la serie de sus hemistiquios.

Los poemas de Dios deseado y deseante y De ríos que se van escritos en verso libre pueden ser analizados con el mismo modelo que hemos aplicado a los primeros versos de Espacio.

${ }^{13}$ Aunque se aceptara un análisis por pies métricos (unidades mínimas del ritmo en el plano teórico), es evidente que, en un poema concreto, nunca se da un pie aislado. 
Como ejemplo, veamos la primera estrofa de "No quiero exaltación de eternidades” (Ddd). ${ }^{14}$

No, dios, no me deslumbres con relumbres, que yo no quiero que esta costumbre recargada de historia acumulada dé relumbre.

Déjame con mis ojos en lo mío, déjame con mi fuego del sol, mi sol de cada día, carbón y luz de cada hora; con la luz de mi hierba verde; con el ansia de lo que quiero contener y retener en mi mirada.

[11] $[5+9]$

[11]

[11]

El verso 8 requiere un comentario. E. Torre (2001: 79-99) ha estudiado a fondo la segmentación del alejandrino, tanto en la poesía francesa como española, y cita precisamente un verso de Juan Ramón Jiménez similar al que analizamos (Torre, 1999: 95): «por la ventana -piedras dentro-, ¡luna blanca!». Se produce en los dos versos un encabalgamiento léxico, pues la cesura rompe la palabre pie / dra, o hier / ba. La primera sílaba se comporta como un monosílabo tónico (acento en $6^{\mathrm{a}}$ ) y, por tanto, el hemistiquio es un heptasílabo. E. Torre expone su posición así: «tales peculiaridades en el verso alejandrino español no son más que variedades rítmicas de un mismo y único patrón métrico: el verso tetradecasílabo, compuesto por dos hemistiquios heptasilábicos» (Torre, 1999: 96).

\section{VARIANTES TEXTUALES EN LA VERSIONES EN PROSA}

Antes de plantearnos la razones por las que Juan Ramón Jiménez decidió presentar como prosa toda su poesía escrita en verso libre, debemos estudiar con criterios filológicos las variantes textuales que diferencian la versión en prosa de la versión en

\footnotetext{
${ }^{14}$ Poema denominado “El desnudo infinito” en su versión definitiva en prosa.
} 
verso libre. A la crítica parece haberle pasado desapercibida la importancia que las variantes textuales tienen para comprender cabalmente el proceso de presentación como prosa y de adaptación rítmica. ${ }^{15}$

La mayoría de las veces, la versión en verso libre no cambia sustancialmente con respecto a la definitiva en prosa. La coincidencia de los finales de verso con las pausas sintácticas o con los grupos fónico-semánticos, facilita que no se altere el texto entre ambas versiones. Véase, por ejemplo, Espacio 1.142-147 y compárese con su versión en prosa:

Entramos por los robles melenudos;

rumoreaban su vejez cascada, oscuros, rotos, huecos, monstruosos, con colgados de telarañas fúnebres;

el viento les mecía las melenas, en medrosos, estraños ondeajes.

Entramos por los robles melenudos; rumoreaban su vejez cascada, oscuros, rotos, huecos, monstruosos, con colgados de telarañas fúnebres; el viento les mecía las melenas, en medrosos, estraños ondeajes,

Podemos comprobar que el texto se mantiene sin cambios y que las pausas sintácticas permiten que en la prosa se "oiga" fácilmente la serie de endecasílabos de la primera versión. Sin embargo, en ocasiones, cuando el final de verso no coincide con pausa sintáctica o final de grupo fónico-semántico

${ }^{15}$ Así, por ejemplo, H. Young apunta: «Esta [supresión de alusiones contemporáneas en el tercer Fragmento] es la única diferencia importante entre las varias versiones de Espacio. Lo demás, aun cuando se trata del cambio del verso libre a la prosa, es sólo una cuestión de la puntuación o alguna que otra palabra» (Young, 1981: 183 n.1). Véase igualmente Albornoz (1982: 66 n.10).«En las dos primeras partes hallamos mínimas variantes enriquecedoras (de palabras y de sintagmas)»; y Villar (1986: 48): «Nació en verso libre [Espacio] en enero de 1941 y así lo continuó Juan Ramón al año siguiente, pero hacia 1953 decidió prosificar todo su verso y Espacio cambió su forma, aunque las variantes sobre los versos sean pocas y sin importancia». 
(encabalgamiento), Juan Ramón Jiménez tiende a alterar el texto de la primera versión. En el verso libre el final de verso, la pausa de final de verso, cumple una función esencial: marcar el límite de la unidad métrica, independientemente de las pausas y unidades sintácticas. Puesto que la prosa carece de esa marca, Juan Ramón Jiménez con frecuencia varía la puntuación y pone comas en la versión en prosa o sustituye comas por pausas más fuertes como el punto y coma. ${ }^{16}$

Encontramos un cambio de puntuación muy significativo en uno de los poemas conservados en dos versiones, en verso libre ("No quiero exaltación de las eternidades") y una segunda versión en prosa ("El desnudo infinito"), incluido en Dios deseado y deseante; véase "No quiero exaltación de las eternidades" 5456:

Que la atmósfera tuya quiera situar[7+7, 7+5]

con una luz o un fuego de aureola cierta, aureola no pintada,

[9]

Compárese con la versión definitiva en prosa de "El desnudo infinito":

Que la atmósfera tuya quiera situar, con una luz o un fuego de aureola, cierta aureola no pintada,

Como puede observarse la nueva puntuación sirve para marcar los límites de las unidades sintáctico-rítmicas de la versión

${ }^{16}$ Sobre la función rítmica de las comas en la prosa de Juan Ramón Jiménez, véase Gullón (1981: 222): "Y esto me lleva a decir algo acerca del uso de la coma en la prosa de Juan Ramón Jiménez. El lector observa en seguida la prodigalidad de signos ortográficos, y especialmente la sobreabundancia de comas [...].En esta breve oración las comas sirven para destacar todos y cada uno de los períodos, que a la vez lo son de ritmo y de significación; ellas dan plenitud a la frase al realzar, enumerándolos, cada uno de los incisos, obligando al lector a fijarse en lo que van añadiendo o, mejor dicho, a notar cómo van completando el sentido de la imagen, transmitiéndonos en su perfección la figura del Achúcarro según la intuyera el poeta”; y Gullón (1981: 223): "En el retrato de Solana es quizá donde el empleo de la coma resalta con trazo más acusado y sirve más eficientemente a la técnica del caricaturista. Las comas separan las imágenes sin aislarlas, y gracias a ellas, como en el ejemplo anterior. La acumulación no estorba al dinamismo del conjunto". 
en prosa: se introduce una coma al final de lo que era el verso 55 y se elimina la coma del verso 56 que producía un encabalgamiento fuerte, de modo que "cierta" determina ahora a la segunda aparición de "aureola”.

Junto a los cambios de puntuación, encontramos otros fenómenos como adiciones, supresiones o sustituciones textuales. Ejemplo: "No quiero exaltación de las eternidades" este fenómeno se repite en varios pasajes; veamos a modo de ejemplo los versos 39-44:

Quiero tu nombre, Dios, orijen nada más; y fin luego y no fin como término sino como propósito.

Quiero, nombrado Dios, que tú esta vez te hagas de veras por mi amor esto que soy, un ente, un ser, un par, un hombre

[11] 40 [?]

[7]

[11]

$[9+5]$

[9]

La dificultad en la medida del verso 40 es evidente: podría ser un octosílabo, inesperado en el métrica general del poema; si consideramos que se produce una diéresis en "lüego", obtenemos un eneasílabo, aunque con acentuación irregular en $1^{\mathrm{a}}, 5^{\mathrm{a}} \mathrm{y}$ $8^{\mathrm{a}}$. La división en dos hemistiquios (2+7) parece arbitraria. Leamos la versión en prosa de este pasaje en "El desnudo infinito":

Quiero tu nombre, dios, orijen nada más y fin; y no fin como término, sino como propósito. Quiero, nombrado dios, que tú te hagas por mi amor esto que soy, un ente, un ser, un hombre,

En primer lugar, observamos que se ha cambiado la puntuación del verso 39 para delimitar mejor la unidad métrica en la prosa, como acabamos de ver. En el verso 40, de difícil medida, se ha eliminado "luego" con lo que se obtiene un heptasílabo nada problemático y además se añade una coma para separarlo del miembro siguiente. El verso 42 ve cómo desaparece “esta vez”; el verso 43, “de veras"; y el verso 44, “un par,", y se introduce una coma al final de este último verso. Estas últimas supresiones no implican obligatoriamente un cambio en la segmentación, aunque ello es posible: 
Quiero tu nombre, dios, orijen nada más y fin; y no fin como término, sino como propósito. Quiero, nombrado dios, que tú te hagas por mi amor esto que soy, un ente, un ser, un hombre,

[11]

[7]

[7]

[7]

$[9+5]$

[7]

\section{Presentación tipográfica y MOdelo de EJeCUCión}

Ha llegado el momento de hacernos la pregunta clave: ¿por qué razón Juan Ramón Jiménez decidió presentar como prosa su producción poética escrita inicialmente como verso libre? Creo que el proceso por el que llegan a confundirse "verso desnudo" y "prosa jeneral”, como llama Juan Ramón Jiménez al verso libre y a su prosa, llena de ritmo, hay que entenderlo como culminación de la desaparición de los límites que separan prosa y verso durante el siglo XIX.

Por conversaciones con R. Gullón (1958: 114-116 y 149) sabemos que Juan Ramón Jiménez tenía la intención de dar forma de prosa a toda su poesía en sucesivas ediciones. Si Gerardo Diego no comprendió el proceso, R. Gullón se escandalizaba ante las intenciones de Juan Ramón Jiménez, que le confesaba su rebelión personal contra la tiranía de la rima (refugio para el poeta débil), la molestia que le producía el "tope del asonante", etc.

[...] no hay prosa y verso [...]; lo que les diferencia es la rima. Si no la hay, todo es prosa, y ésta puede recortarse y escribirse en verso. Por eso estoy pensando, para sucesivas ediciones de mis obras, en dar el verso como prosa. -iNo haga eso!- le pido [...]; a muchos lectores les produciría, inútilmente, gran confusión-. ¿Por qué no hacerlo? -replica-. Tome un poema y recítelo pensando que todos los oyentes son ciegos. Precisamente, la mayoría de los lectores se hacen cargo del poema, en primer término, por como lo 
ven. El verso libre es prosa y puede escribirse como tal. Si no fuera por la rima no habría verso, y no encuentro inconveniente en que el poema se escriba seguido (Gullón, 1958: 114-115). ${ }^{17}$

La cercanía de verso libre y prosa rítmica, prosa jeneral, para Juan Ramón Jiménez se desprende de su combinación en poemarios como Diario de un poeta recién casado, Dios deseado y deseante y De ríos que se van, pero sobre todo de los numerosos poemas que presentan dos versiones, una en verso y otra en prosa. Estos poemas comparten el ritmo endecasilábico con los poemas de los que sólo conservamos o bien la versión en verso libre o bien la versión en prosa. La indiferenciación de estas variedades poéticas en la conciencia de Juan Ramón Jiménez se acrecienta cuando observamos que Juan Ramón Jiménez lee sus poemas de acuerdo con un "modelo de ejecución” expresivo, es decir guiado por la sintaxis y la semántica. ${ }^{18}$ Es decir, en su lectura no se produce pausa entre los versos encabalgados. Por tanto para Juan Ramón Jiménez, la lectura de un poema como Espacio en su versión en verso libre no se diferencia de la lectura de la versión en prosa. Su “ejemplo de ejecución” de Espacio explica su concepción de que para un ciego no se diferencian verso y prosa (Juan Ramón Jiménez "Poesía cerrada y poesía abierta”):

Para un ciego el verso y la prosa serían iguales. Y en realidad no existe el verso más que por el consonante o el asonante, por la rima.

Para Juan Ramón Jiménez la división en líneas era un artificio tipográfico, por eso en numerosos lugares de su producción crítica insiste en la imagen del ciego. Es evidente que al suprimir los saltos de línea, Juan Ramón Jiménez pretendía hacer concorde la tipografía con el modelo de ejecución que él adoptaba: la lectura como prosa, sin marcar los finales de verso con una pausa.

${ }^{17}$ Conversación mantenida el 10 de diciembre de 1952.

${ }^{18}$ Para los conceptos “modelo de ejecución” y “ejemplo de ejecución”, véase Domínguez Caparrós, 1993: 41-43. 
Ambos fenómenos son coherentes y restan énfasis al poema, cuando se lee o cuando se oye; unas palabras de Juan Ramón Jiménez dejan patente la cercanía de esos dos fenómenos:

Cuando leemos poesía lo que se busca es el tope del asonante. El lector parte el romance con el ojo, porque tiene que leer y va hasta el final de cada línea para volver luego al comienzo de la otra. Conviene siempre evitar eso y el latiguillo del recitado (Juan Ramón Jiménez, citado por Gullón: 149).

Juan Ramón Jiménez no sólo anula las pausas de finales de verso en su "ejemplo de ejecución", sino también expresa claramente su disgusto ante el "tope del asonante" (Gullón). Así pues, es coherente que decidiera dar forma de prosa a su poesía. No podemos obviar el hecho que «la disposición gráfica es importante, por cuanto que manifiesta la intención rítmica del autor» (Domínguez Caparrós, 1993: 33). Quizá uno de los objetivos que Juan Ramón Jiménez pretendía con la presentación tipográfica como prosa de sus poemas escritos inicialmente en verso libre fuera que los "ejecutaramos" siguiendo el modelo sintáctico-semántico que él solía adoptar.

\section{Verso dESNUdo y PROSA JENERAL}

El fenómeno es muy complejo, y postular que la "prosa" de la etapa americana de Juan Ramón Jiménez no es más que verso libre enmascarado tipográficamente es simplificar el problema. Refiriéndose a las formas poéticas que Juan Ramón Jiménez creía todavía válidas, escribió las siguientes palabras (Juan Ramón Jiménez "Poesía cerrada y poesía abierta”):

Canción, romance y verso libre (y prosa jeneral) son las tres formas en que yo libertaría hoy gustosamente toda la poesía española o, al menos, la mía. 
A partir de esta declaración, no es difícil discernir que Juan Ramón Jiménez consideraba que verso libre y “prosa jeneral” se subsumen en una sola forma, que se diferencia del verso (canción, romance) por la rima, como veíamos en las citas anteriores de Gullón. La misma opinión aparece en "Poesía abierta y poesía cerrada":

para un ciego el verso y la prosa serían iguales. Y en realidad no existe el verso más que por el consonante o el asonante, por la rima. El ciego es siempre una gran autoridad para la escritura poética.

Para Juan Ramón Jiménez, el verso, el verso libre y la prosa comparten la organización rítmica y el verso libre y la prosa se diferencian del verso porque no tienen rima. Así pues, la prosa para Juan Ramón Jiménez no se distingue rítmicamente en nada del verso libre, luego la presentación tipográfica carece de importancia.

De hecho, los poemas de los que sólo conservamos su presentación en prosa, bien porque se haya perdido su versión en verso libre o bien porque ésta nunca existiera, presentan el mismo ritmo endecasilábico que los que fueron escritos en verso libre. El fenómeno ha sido estudiado por E. Torre, quien recoge este interesante fenómeno en Métrica española comparada:

En ocasiones, el autor decide escribir su poema con la apariencia tipográfica de la prosa. En un grado más avanzado de 'liberación' de las ataduras del metro, pasaríamos así del verso libre al poema en prosa:

Gracias, ta las doy siempre. ¿A quién las doy? A la belleza inmensa se las doy, que yo soy bien capaz de conseguir; que tú has tocado, que eres tú. Sila belleza inmensa me responde o no, yo sé que no te ofendo ni la ofendo. (Juan Ramón Jiménez)

Pero una segmentación del poema, como la que sigue, nos revelará un conjunto de versos totalmente regulares:

Gracias, ta las doy siempre. ¿A quién las doy? A la belleza inmensa se las doy, 
que yo soy bien capaz de conseguir;

que tú has tocado, que eres tú.

Si la belleza inmensa me responde

o no, yo sé que no

te ofendo ni la ofendo. (Juan Ramón Jiménez) (Torre, 2000: 105)

Este análisis en segmentos métricos propuestos por el Profesor Torre se basa naturalmente en el ritmo endecasilábico (11, 11, 11, 9, 11, 7, 7), que hemos visto a propósito de Espacio.

En la última etapa de Juan Ramón Jiménez, su "verso desnudo" y su "prosa jeneral” son indiferenciables rítmicamente. Su poética en ese punto busca una expresión formal en la presentación tipográfica como prosa. Esa forma común, que engloba verso libre y prosa rítmica; “verso desnudo” y “prosa jeneral”, y que puede aparecer bajo forma de verso o de prosa, no es una forma intermedia entre versificación regular y prosa. Más bien, es la evolución coherente desde el verso libre; es una depuración más del verso libre, al que se le quita otro componente "artificial”: el tope de fin de verso. En esta evolución liberadora, quizá haya sido uno de los factores principales el versículo, que, sin la limitación del verso ni la continuidad de la prosa, posee una naturaleza intermedia. El versículo se segmenta rítmicamente sin tener en cuenta la marca visual de final de verso ni las unidades sintáctico-semánticas. Es como si Juan Ramón Jiménez, al convertir en prosa los maravillosos versos de Espacio, hubiera formado un único e interminable versículo.

\section{Coherencia EN EL PLANTEAMiento}

Volvamos a enunciar la razón por la que Juan Ramón Jiménez presenta esta poesía escrita en verso libre como prosa: el poeta distingue dos formas genéricas, que incluyen naturalmente diversas variedades:

1) el verso, necesariamente con rima asonante o consonante, que puede ser romance, canción, etc. 
2) El verso libre, que carece de rima, y que no se distingue de la prosa y por tanto es susceptible de ser presentado tipográficamente como prosa.

Juan Ramón Jiménez no pensaba que se trataba de una concepción rítmica sin importancia y pretendió ser coherente hasta el extremo. Así, el poema titulado "El terrible desvelo" supone un terrible descubrimiento. Cito palabras literales de Alegre para que nos hagamos una idea de la historia textual de esta composición:

He visto tres originales de este poema; el más antiguo se titula "Más que la muerte y la nada", luego tachado y sustituido por "El sueño terrible"; este original, escrito en verso, está lleno de correciones y variantes manuscritas del poeta, y fechado en 1952 con una interrogante. El segundo original lleva el título de "El terrible sueño” y no tiene ningún tipo de anotación manuscrita. Por último, el original más reciente, del que partimos en esta edición se titula "El terrible desvelo", está fechado en 1951 y en la parte superior izquierda de la página se lee: «De ríos que se van: 3» (Alegre, 1999: 480).

Antes de ver los originales en verso, al intentar analizar en miembros el poema, se encuentra uno con dificultades casi insalvables: no hay forma ni medio de encontrar ningún verso de ritmo endecasilábico, ni comenzando por el principio ni comenzando por el final. Parece prosa sin ritmo:

Estás sola de ti misma, sola mía, más de ti que de mí que más te quise que tú te quisiste...

¿Y cómo podrá ser que estés tan sola si estuve todo contigo? ¿No quepo en tu soledad?

Yo soy más grande por ti que mi vida y que mi muerte; y quepo donde tú estés tan sola en ti misma.

¡No, no me lo puedes decir; eres más grande que yo, eres más grande que el mundo, eres más grande que el cielo, más que la muerte y la nada!

¡Eres ya tu eternidad!

¡No sé qué hacer con lo mío! 
El problema se presenta casi irresoluble, si se aplica el método habitual: la sorpresa es que, midiendo con rigor, se comprueba que se trata de un poema escrito en octosílabos:

Estás sola de ti misma, sola mía, más de ti que de mí que más te quise que tú te quisiste... ¿ ¿Y cómo podrá ser que estés tan sola si estuve todo contigo? ¿No quepo en tu soledad? Yo soy más grande por ti que mi vida y que mi muerte; y quepo donde tú estés tan sola en ti misma. ¡No, no me lo puedes decir; eres más grande que yo, eres más grande que el mundo, eres más grande que el cielo, 15 más que la muerte y la nada! ¡Eres ya tu eternidad! ¡No sé qué hacer con lo mío!
[8]

5

[8]

[8]

10

[8]

[8]

[8]

[8]

[8]

[8]

[8]

[8]

[8]

Cuando al finales del año 2001, durante una estancia de investigación en la Sala Zenobia y Juan Ramón Jiménez de la Universidad de Puerto Rico, pude colacionar los originales en verso a los que se refería Alegre, su lectura confirmó este análisis en octosílabos.

Teniendo en cuenta estas reflexiones sobre el carácter de la rima, que clasificaría para Juan Ramón Jiménez un texto como verso o como prosa, podemos comprender la razón que llevó al poeta a presentar como prosa un poema escrito en octosílabos, "El terrible desvelo", donde sólo los versos 11 y 13 parecen presentar el fenómeno de la rima:

tan sola en ti misma. ¡No, no me lo puedes decir; eres más grande que yo, 
La importancia de la prosificación de este poema es esencial, en tanto demuestra que la prosificación no afecta sólo a los poemas en verso libre de ritmo endecasilábico ni está determinada sólo por la cercanía del verso libre y la prosa, sino que descansa fundamentalmente en la existencia o carencia de rima.

\section{7. ¿Y LA RIMA EN ESPACIO?}

Ahora bien, el problema se va complicando porque en los poemas escritos en verso libre de ritmo endecasilábico que Juan Ramón Jiménez presentó como prosa (Espacio, y otros pertenecientes a los dos últimos poemarios, Dios deseado y deseante y De ríos que se van), la rima no ha desaparecido ni siquiera es un fenómeno esporádico, como se cree generalmente. La rima es un componente esencial en este tipo de verso libre, como he demostrado en un reciente artículo publicado en Hispanic Review sobre la poesía última de Aleixandre (Márquez, 2001).

Así pues, la coherencia juanramoniana que le lleva a presentar como prosa las composiciones que se clasificaría como "verso desnudo" parece encontrar una falla insoluble cuando comprobamos que la rima juega un papel importante en poemas como Espacio, a pesar de la opinión expresada por el poeta contra la rima tanto asonante como consonante en su última época. ${ }^{19}$

Tres aspectos destacan en la rima del verso libre de Espacio: la gran cantidad de versos con rima (el 29\%); las numerosas disposiciones que adopta; y las funciones rítmicas y eufónicas que desempeña. La descripción de las numerosas variedades tiene dos objetivos: por una parte, hacer ver la importancia cualitativa

${ }^{19}$ Recogidas por Domínguez Caparrós (1999: 152): “El consonate lo aborrezco hoy creo que nos quita nuestra poesía para darnos la suya, nos hace esclavos. Ejemplo, Jorge Guillén, el poeta virtuoso más esclavo, en su limitación, del verso impuesto desde fuera. El asonante tampoco me gusta hoy más que en la canción y en el romance, donde es tan naturalmente español. Ejemplo, Bécquer. En el verso libre todo es uno, nada viene traído de la palabra aconsonantada ni de la asonantada". Domínguez Caparrós ha analizado el funcionamiento de la rima en dos poemas de Juan Ramón Jiménez, “Paisaje del corazón” y “El idilio”. 
y cuantitativa de la rima en unos poemarios escritos en verso libre y, por tanto, en los que no se espera a priori su aparición; por otra parte, aportar los datos suficientes para desterrar cualquier sospecha de subjetivismo. ${ }^{20}$ Dejando al margen todos los fenómenos de rimas extrasisteméticas estudiados por Domínguez Caparrós (1997 y 1999), y limitándonos a la definición tradicional de rima, encontras en Espacio las siguientes disposiciones:

1) Rima pareada, Espacio 1.104-112:

me rodean, me envuelven en su ritmo, en su gracia, en su fuerza delicada, y yo me olvido de mí entre ello, y bailo y canto, y río y lloro por los otros, embriagado. ¿Esto es vivir? ¿Hay otra cosa más que este vivir de cambio y gloria? Yo oigo siempre esa música que suena en el fondo de todo, más allá; ella es la que me llama desde el mar;

2) Rima cruzada, Espacio 2.20-23:

otra vez, de mi soledad y mi silencio, tan igual en mi piso $9 \mathrm{y}$ sol, al cuarto bajo de mi calle y cielo. Dulce como este sol es el amor.

3) Rima abrazada, Espacio 1.242-245:

Todo lo rodeaban piedra, cielo, río; y cerca el mar, más muerte que la tierra, el mar lleno de muertos de la tierra, sin casa, separados, engullidos

${ }^{20}$ Se cita un solo ejemplo de cada esquema de rima, auqnue los datos podrían multiplicarse. 
4) Rima continua, se aducen ejemplos al tratar la rima idéntica y la rima interna.

5) Rima alterna, Espacio 1.184-188:

escena fiel, que yo, que la creaba, creía de otros más que de mí mismo.

Los otros no lo vieron; mi nostaljia, que era de estar con ellos, era de estar conmigo, en quien estaba.

6) Rima con esquema a, ø, ø, a, Espacio 1.253-256:

viene a mis manos, ya más duras, como un cordero blanco a beber la dulzura ${ }^{21}$ del amor.

Amor el de Eloísa; qué ternura,

7) Rima con esquema a, ø, a, Espacio 1.117-123:

¡Qué letra, luego, la suya!

El músico mayor tan sólo la ahuyenta.

Pobre del hombre

si la mujer oliera, supiera siempre a rosa.

¡Qué dulce la mujer normal, qué tierna, qué suave (Villon), qué forma de las formas,

En este último ejemplo hallamos también una caso de rima interna (ahuyenta-oliera). La rima interna precisa un análisis más detallado; adopta diversos esquemas entre los que destacan los siguientes: final de verso y final de hemistiquio del verso siguiente; finales de los primeros hemistiquios de versos consecutivos; finales de los hemistiquios de un mismo verso (rima leonina); véase, por ejemplo, Espacio 1.241:

21 “dulzura” no entra estrictamente en esta rima, pero sobre esa palabra recae el acento rítmico de $6^{\mathrm{a}}$ sílaba. 
Como en el lento anochecer, del lento amanecer [9+7]

Por otra parte, hallamos en Espacio casos de rima idéntica. La preceptiva rechaza unánimemente su uso. Sin embargo, sus posibilidades expresivas hacen que la encontremos en todas las épocas y lenguas europeas. Micó ha estudiado exhaustivamente su empleo en la poesía de Herrera y, al final de su trabajo, alude a su pervivencia en la poesía de la generación del 27 y cita un bello ejemplo de Borges. La presencia de rimas idénticas presupone la conciencia poética del fenómeno, puesto que no se puede achacar a descuido si se encuentra reiterada o se acompaña de otros recursos basados en la repetición. Espacio presenta numerosos casos de rima idéntica. Véase el siguiente, como ejemplo, Espacio 1.330-334:

Yo te oí, perro, siempre, 330

desde mi infancia, igual que ahora; tú no cambias

en ningún sitio, eres igual

a ti mismo, como yo. Noche igual,

Juan Ramón Jiménez a veces utiliza la rima idéntica con un matiz en la diferenciación de significado, rasgo por el que la preceptiva admite ocasionalmente este uso; en Espacio 1.93-95 parece percibirse un significado diferenciado del verbo "volverse”, “darse la vuelta” y “devolvérsenos”:

Hermoso no tener lo que se tiene, nada de lo que es fin para nosotros, es fin, pues que se vuelve contra nosotros, y el fin nunca se nos vuelve.

Si nos adentramos en la funciones que la rima desempeña en el verso libre, comprobamos que, como señala Domínguez

\footnotetext{
${ }^{22}$ Esta última aparición de “igual” no puede considerarse una rima, pero en esa palabra recae el acento rítmico de $6^{\mathrm{a}}$ sílaba.
} 
Caparrós (1997: 1), la rima es, al mismo tiempo, un fenómeno eufónico y rítmico. Se diferencia de otros hechos eufónicos por su función rítmica y es evidente que ayuda a percibir la segmentación poética. El verso libre, en el que el patrón métrico está establecido menos rigurosamente que en la versificación tradicional, utiliza frecuentemente la rima como un elemento rítmico necesario. Pero además la rima interna, como la final, provoca una repetición en el curso de la frase; el sonido que se repite nos devuelve, por un instante, como si fuera un eco, la palabra del verso anterior. La rima interna de la poesía en verso libre facilita la percepción de los hemistiquios. El recurso se hace tan general que se emplea incluso con los alejandrinos no necesitados de ese apoyo, Espacio 1.389-390:

Que mi oído es tan justo por tu canto;

ajústame tu canto más a este oído mío

Mediante la rima interna se percibe más fácilmente la segmentación en hemistiquios de los versos compuestos y se puede seleccionar la medida correcta, descartando otras posibilidades permitidas por la secuencia acentual y el cómputo silábico. Así, por ejemplo, en Espacio 1.276-277, la rima interna gracia-hermana selecciona la medida $7+7$ para el segundo verso, frente a una medida 5+9 posible por la serie acentual y el cómputo silábico:

De la dulce obediente, plena gracia.

Amante, madre, hermana, niña tú, Eloísa

O en Espacio 1.124-125 la rima idéntica e interna (sustanciasustancias) selecciona la medida $5+11$, frente a la posible $9+7$ :

Qué esencia, qué sustancia

de las sustancias, las esencias, qué lumbre de las lumbres

Domínguez Caparrós (1997: 14) ha señalado que la rima en el verso libre refuerza su función eufónica por un desdibujamiento 
de su tradicional función rítmica. ${ }^{23}$ En este sentido, Espacio 1.150-157 nos proporciona ejemplos de rimas y asonancias expresivas: "rico" (acento rítmico de $4^{\mathrm{a}}$ sílaba), "grito", "gritillos" (acento rítmico de 6 a sílaba), "niños” parecen evocar los sonidos que denotan y se adscriben a la vida; por el contrario, la asonancias en $e$-o que le siguen sugieren todo lo mortuorio:

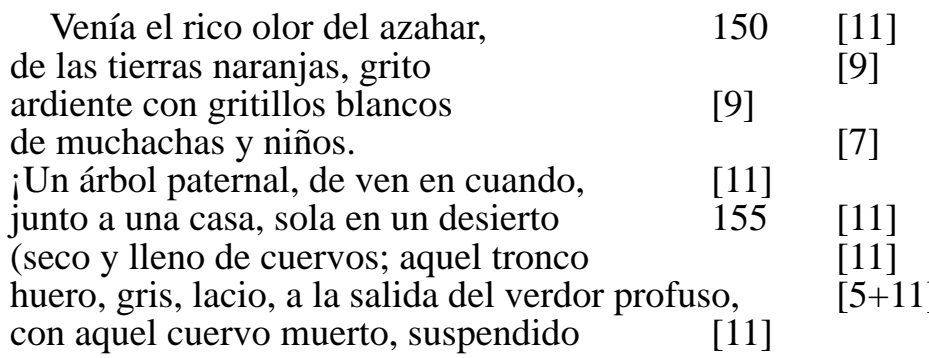

\section{El Prosimetrum final de Juan Ramón JimÉneZ}

Pero podemos estar seguro de que Juan Ramón Jiménez en sus últimos años percibió esta contradicción o esta incoherencia: presentaba como prosa su "verso desnudo" porque no tenía la rima del romance o la canción, pero el poeta debió descubrir que esas composiciones contenían esencialmente fenómenos de rima (casi un tercio de los versos contienen fenómenos de rima). Por eso, Juan Ramón Jiménez adoptó ya en los años cincuenta una nueva forma genérica que combinaba la prosa y el verso, y de la que la crítica parece no haber dicho nada.

23 “quizá la rima, en la época del verso amétrico, no tiene más función que la meramente eufónica, de leve contraste entre sonidos que se repiten y lo que no, para producir la sensación del tiempo sobre el recuerdo. [...] La rima parece cambiar al mismo tiempo que los otros factores rítmicos. ¿Qué sentido tiene la rima, aparte de su carácter eufónico, en los versos libres, por ejemplo? Y sabemos que se ha empleado la irma también en el verso libre. Pero volviendo, lógicamente, al campo del que salió, al campo retórico de la eufonía” (Domínguez Caparrós, 1997). 
Algunos poemas escritos en "verso desnudo" de la última época adoptan una disposición especial, muy característica y novedosa, como he podido comprobar en la Sala Zenobia y Juan Ramón Jiménez. Encontramos originales mecanografiados que comienzan con presentación tipográfica de prosa: son poemas compuestos de segmentos rítmicos endecasilábicos (para nosotros serían versos escritos en verso libre de ritmo endecasilábico presentados como prosa). De pronto, Juan Ramón Jiménez adopta una nueva disposición tipográfica: ahora con sangría y con saltos de línea. Y tras una estrofa, se vuelve a la tipografía de prosa.

¿Cuándo ocurre esto, cuándo se cambia de la tipografía de prosa al verso? Naturalmente cuando se producen fenómenos de rima; pero deberemos observar que en nada ha cambiado el ritmo. A esta forma que combina las tipografías de la prosa y del verso podríamos denorminarla prosimetrum, recogiendo la terminología de un fenómeno similar que se da en la Antigüedad tardía.

Este fenómeno no ha llamado la atención de la crítica y ha pasado desapercibido a algunos editores tan minuciosos como Alegre. Incluso en algunas composiciones de Leyenda, Sánchez Romeralo ha susituido la forma original de prosimetrum por una simple forma en prosa.

Vamos a ver el poema titulado "Sobre una nieve (Entre un sol y la eternidad)", perteneciente a De ríos que se van. En todas las ediciones [Tercera antolojía poética, Leyenda y la edición reciente de Alegre, Lírica de una Atlántida] aparece esta composición como pura prosa.

Ni su esbeltez de peso exacto, tendida aquí, mi mundo, y como para siempre ya; ni su a veces verde mirar de fuente ya con agua de sol sólo; ni el descenso sutil de su mejilla a la callada cavidad oscura de la boca; ni su hombro pulido, tan rozado ahora de camelia diferente; ni su pelo de oro gris un tiempo, luego negro, ya absorbido en valor único; ni sus manos menudas que tanto trajinaron en todo lo del día y de la noche, y sobre todo en máquina y en lápiz y en pluma para mí; ni..., me dijeron, por suerte mía: 
Mi encanto decisivo residía, ¡acuérdate tú bien, acuérdate tú bien!, en algo negativo que yo de mí tenía; como un aura de sombra que exhalara luces de un gris, sonidos de un silencio (y que ahora será de la armonía eterna), incógnita fatal de una belleza libertada; residente, sin duda y más visible quizás en los eclipses.

Por mi suerte, quedó la eternidad para más tarde; y ella salió, como después me dijo, por la otra boca del pensado túnel y vio salir también el rojo sol sobre la nieve.

De este poema he tenido la suerte de encontrar cinco versiones distintas en la Sala Zenobia y Juan Ramón Jiménez. Cuatro de estas versiones coinciden en líneas generales con las ediciones de Sánchez Romeralo y Alegre, aunque presentan pequeñas variantes textuales sin importancia decisiva. Pero resulta que la quinta versión presenta la peculiar presentación tipográfica que combina verso y prosa:

Ni su esbeltez tendida aquí, mi mundo, y para siempre ay; ni su verde mirar de fuente ya con agua de solo solo; ni el descenso sutil de su mejilla a la callada cavidad oscura de la boca; ni su hombro plasmado y tan rozado de camelia diferente; ni su pelo de oro gris un día, luego negro, ya absorbido; ni sus manos menudas que tanto trajinaron en todo y sobre todo en máquina y en pluma para mí; me dijeron, por suerte para mí -mía-:

Mi encanto decisivo residió en algo negativo que yo de mí tenía, como un aura de sombra que exhalaba (y que ahora será de la armonía eterna) luces de un gris, sonidos de un silencio, incógnita fatal de una belleza más visible, sin duda, en los eclipses.

Por mi suerte, salió, como después me dijo, por la otra boca del pensado tunel y vio salir también el sol sobre la nieve. 
En este poema la forma de prosimetrum es especialmente significativa y emotiva: son palabras en estilo directo de Zenobia, tras la operación a la que se sometió en Boston, mientras que el poeta permanecía hospitalizado en Puerto Rico. Al día siguiente de la operación, Zenobia le escribió una carta a Juan Ramón en la que decía: «Queridísimo Juan: estoy en el sitio más lindo que puedas imaginar porque después de la nevada de ayer ha salido el sol y el mundo está limpio y reluciente»; alegre cree que estas palabras de Zenobia sirvieron de punto de partida del poema. En cualquier caso, su contenido es conmovedor.

Hagamos una comparación exhaustiva. Segmentación métrica del primer párrafo en las ediciones de Sánchez Romeralo y Alegre. En las primeras unidades, hay una reducción sensible (un esfuerzo de concisión evidente), se pasa de 48 sílabas métricas a $36(9+9+9+7+7+7$ a $11+7+11+7)$.

Ni su esbeltez de peso exacto,

tendida aquí, mi mundo,

y como para siempre ya;

ni su a veces verde

mirar de fuente ya

con agua de sol sólo;

Y su versión definitiva según uno de los originales de Puerto Rico:

Ni su esbeltez tendida aquí, mi mundo, y para siempre ay; ni su verde mirar de fuente ya con agua de solo solo;

El texto en líneas generales se mantiene, con alguna supresión y en el final de ese primer párrafo volvemos a encontrar el mismo esfuerzo de concisión:

ni sus manos menudas

que tanto trajinaron

en todo lo del día y de la noche, 
y sobre todo en máquina y en lápiz en pluma para mí; ni..., me dijeron, por suerte mía:

ni sus manos menudas

que tanto trajinaron

en todo y sobre todo

en máquina y en pluma para mí;

me dijeron, por suerte

para mí -mía-:

Hay una reducción y, sobre todo, una reorganización de las unidades rítmicas. Ahora bien, los grandes cambios se producen, en el segundo párrafo, que transmite el estilo directo, y que va a pasar a forma de verso, frente al primero y al tercero que conservan la forma de prosa. Veamos, en primer lugar, la segmentación del texto de Leyenda:

Mi encanto decisivo residía, ¡acuérdate tú bien, acuérdate tú bien!, en algo negativo que yo de mí tenía; como un aura de sombra que exhalara luces de un gris, sonidos de un silencio

(y que ahora será de la armonía eterna), incógnita fatal de una belleza libertada; residente, sin duda y más visible quizás en los eclipses.

Mi encanto decisivo residía en algo negativo que yo de mí tenía, como un aura de sombra que exhalaba (y que ahora será de la armonía eterna) luces de un gris, sonidos de un silencio, incógnita fatal de una belleza más visible, sin duda, en los eclipses. [11] 
Hay una reducción sustancial desde la versión en prosa y la final que adquiere forma de prosimetrum; la eliminación de texto busca reforzar los fenómenos de rima y aproximarlos. Así pues, esta forma del prosimetrum deberá tenerse en cuenta para las nuevas ediciones de los poemarios de la etapa americana de Juan Ramón Jiménez.

\section{Bibliografía}

ACEREDA, A. (1995) "Juan Ramón Jiménez y el verso libre en la poesía española: Del simbolismo francés al Diario de un poeta recién casado”, Estudios Humanísticos: Filología 17, 11-27.

ALBORNOZ, AURORA DE (1982) “Estudio de la obra”, en Espacio, Madrid: Editora Nacional.

ALEGRE HEITZMANN, A. (1999) "Prólogo y notas”, Lírica de una Atlántida, Barcelona: Círculo de Lectores-Galaxia Gutenberg.

BERMÚDEZ-CAÑ̃TE, F. (1981) "Notas sobre la prosa poética en Juan Ramón Jiménez”, Cuadernos Hispanoamericanos 376-378, 768-776.

BLASCO, J. Y GÓMEZ TRUEBA, T. (1994) Juan Ramón Jiménez: la prosa de un poeta, Valladolid: Grammalea.

CORNULIER, BENOÎT DE (1984) "Des vers dans la prose. Une strophe de Bremond-Vauglas", Poétique 57, 76-80.

DEVOTO, D. (1980-1982): "Leves o aleves consideraciones sobre lo que es el verso", Cahiers de Linguistique Hispanique Médiévale 5, 67-100; 7, 5-60.

DIEGO, G. (1984) "Recuerdos y poemas de Juan Ramón”, en Crítica y poesía, Madrid: Júcar, 325-354.

DOMÍNGUEZ CAPARRÓS, J. (1988a) Métrica y poética. Bases para la fundamentación de la métrica en la teoría literaria moderna, Madrid: UNED.

- (1988b) "Los conceptos de modelo y ejemplo de verso, y de ejecución”, Epos IV, 241-258.

-(1988b) Contribución a la bibliografía de los últimos treinta años sobre la métrica española, Madrid: CSIC.

-(1988c) "Prosa y verso", en Métrica y Poética. Bases para la fundamentación de la Métrica en la Teoría Literaria Moderna, Madrid: UNED, 21-30.

-(1990) "Métrica y poética en Rubén Darío”, en El Modernismo. Renovación de los lenguajes poéticos, ed. T. Albaladejo, J. Blasco y R. de la Fuente, Valladolid: Universidad de Valladolid, 31-46.

— (1992) “La métrica y los estudios literarios”, Epos VIII, 245-260. 
- (1993) Métrica española, Madrid: Síntesis.

- (1997) "La rima: entre el ritmo y la eufonía”, Eutopías. Documentos de trabajo 175, 1-20.

- (1999a) Estudios de métrica, Madrid: UNED.

-(1999b) "El modernismo en la formación del verso español contemporáneo”, en J. Domínguez Caparrós Estudios de Métrica, 181 $-207$.

-(2000) “Métrica clásica y verso moderno”, en Miguel Á. Márquez, A. Ramirez de Verger y P. Zambrano (eds.) El retrato literario. Tempestades y naufragios. Escritura y reelaboración, Actas del XII Simposio de la SELGYC, Huelva: SELGYC y Universidad de Huelva, 49-69.

GÓMEZ REDONDO, F. (2001) "Versolibrismo y regularidad métrica: la ‘forma libre’ de Juan Ramón Jiménez”, Signa 10, 251-268.

GULLÓN, R. (1958) Conversaciones con Juan Ramón Jiménez, Madrid: Taurus.

GULLÓN, R. (1968) El último Juan Ramón Jiménez, Madrid-Barcelona: Alfaguara.

MÁRQUEZ, M. A. (2000) "El versículo en el verso libre de ritmo endecasilábico”, Bulletin of Hispanic Studies LXXVII, 217-234.

MÁRQUEZ, M. A. (2001) "La rima en la poesía última de Vicente Aleixandre”, Hispanic Review 69, 337-353.

- (2002) "El poema en prosa y el principio antimétrico", Epos, en prensa.

PARAÍSO, I. "Métrica y lenguaje poético en Baladas de Primavera de Juan Ramón Jiménez”, en En el texto de Juan Ramón Jiménez, Actas del $14^{\circ}$ curso de verano San Roque, Cádiz, Universidad, 7-21.

- (1971) "El verso libre de Juan Ramón Jiménez en Dios deseado y deseante”, Revista de Filología Española, LIV (3-4), 253-269.

-(1976) Juan Ramón Jiménez. Vivencia y palabra, Madrid: Alhambra.

-(1976) Teoría del ritmo de la prosa (aplicada a la hispánica moderna), Barcelona: Planeta.

- (1985a) El verso libre hispánico. Origenes y corrientes, Madrid: Gredos.

- (1985b) "Juan Ramón Jiménez o la consagración de la silva libre impar”, en El verso libre hispánico, Madrid: Gredos, 200-206.

-(2000) La métrica española en su contexto románico, Madrid: Arco/ Libros.

RAFOLS, W. DE (1995) "On the Genre of 'Espacio (3 estrofas)': The Camouflaged Verses”, Hispanic Review 63 (3), 363-385.

ROMERO LÓPEZ, D. (1992) "Juan Ramón Jiménez 1900: hallazgo del eslabón perdido entre la selva modernista y el verso libre hispánico”, Cuadernos de Investigación Filológica XVIII (1 y 2), 99-107.

SÁNCHEZ ROMERALO, A. (1978) "Prólogo-epílogo", Juan Ramón Jiménez. Leyenda, Madrid: Cupsa. 
TORRE, E. (1986) “El verso y sus elementos”, en E. Torre y M.A. Vázquez, Fundamentos de poética española, Sevilla: Alfar, 23-58.

-(1994) "La traducción del verso", en E. Torre, Teoría de la traducción literaria, Madrid: Síntesis.

-(1998) La poesía de Grecia y Roma, ejemplos y modelos de la cultura literaria moderna, Huelva: CSIC-Universidad de Huelva.

-(1999) El ritmo del verso, Murcia: Universidad de Murcia.

- (2000) Métrica española comparada, Sevilla: Universidad de Sevilla. UTRERA TORREMOCHA, M.V. (1999) Teoría del poema en prosa, Sevilla: Universidad de Sevilla.

-(2001) Historia y teoría del verso libre, Sevilla: Padilla.

YOUNG, H.T. (1967) Juan Ramón Jiménez, Nueva York-Londres, Columbia University Press.

- (1981) "Génesis y forma de 'Espacio' de Juan Ramón Jiménez”, en Albornoz, A. (ed.) Juan Ramón Jiménez, Madrid: Taurus, 183-193, [ (1968) Revista Hispánica Moderna, Año XXXIV, n. 1-2, Nueva York]. 